\title{
Highlights and comments on EHRA/HRS/APHRS/LAHRS expert consensus on risk assessment in cardiac arrhythmias: use the right tool for the right outcome
}

\author{
Márcio Jansen de Oliveira Figueiredo ${ }^{1}\left(\mathbb{D} \cdot{\text { Gerardo Rodriguez } \text { Diez }^{2} \cdot \text { Santiago Nava-Townsend }}^{3} \cdot\right.$ Alberto Alfie $^{4}$. \\ Carina Hardy ${ }^{5}$. Dario Di Toro ${ }^{6}$ Manlio F. Márquez ${ }^{3}$
}

Received: 22 February 2021 / Accepted: 7 April 2021 / Published online: 19 April 2021

๑) Springer Science+Business Media, LLC, part of Springer Nature 2021

\begin{abstract}
Patients with heart disease, or at high risk of developing a cardiac condition, usually undergo risk assessment by primary care physicians, internal medicine doctors, or cardiologists. There are several methods that can be used for this risk assessment, and their applicability differs with respect to availability, complexity, and usefulness in different geographic populations. This document focuses on some of the many relevant clinical topics recently presented in the "Expert Consensus on Risk Assessment in Cardiac Arrhythmias: Use the Right Tool for the Right Outcome," which include statements based on the best available evidence. In this review, we want to highlight and make some pertinent comments on some of the most relevant points of this Consensus.
\end{abstract}

Keywords Cardiac arrhythmias · Cardiac electrophysiology · Electrocardiography · Invasive electrophysiological study · Atrial fibrillation $\cdot$ Ventricular tachycardia

\section{Introduction}

One of the most important roles for professional medical societies is to develop expert consensus guidelines and documents that can help define policies and strategies for the best medical care of our patients. Heart Rhythm societies and associations all over the world are focused on the field of

Márcio Jansen de Oliveira Figueiredo

mjofig@gmail.com

1 Cardiology, Electrophysiology Service, University of Campinas (UNICAMP) Hospital, Campinas, Brazil

2 Department of Electrophysiology and Hemodynamic, Arrhytmias Unity, CMN 20 de Noviembre, ISSSTE, Mexico City, Mexico

3 Department of Electrocardiology, National Institute of Cardiology "Ignacio Chavez”, Mexico City, Mexico

4 Division of Electrophysiology, Instituto Cardiovascular AdventistaClinica Bazterrica, Buenos Aires, Argentina

5 Arrhythmia Unit, Heart Institute, University of São Paulo Medical School, Instituto do Coração -InCor, São Paulo, Brazil

6 Department of Cardiology, Division of Electrophysiology, Argerich Hospital and CEMIC, Buenos Aires, Argentina arrhythmia diagnosis and management and gather clinical and interventional electrophysiologists that could work on many of these documents to address many critical clinical topics. From a continental point of view, there are four such societies: Latin American Heart Rhythm Society (LAHRS), Heart Rhythm Society (HRS), European Heart Rhythm Association (EHRA), and Asian Pacific Heart Rhythm Society (APHRS). All have a similar interest and expertise in many relevant topics on the field, emphasizing that best arrhythmia management is a collaborative process among multiple professional societies from around the world.

Recently these four Societies developed an Expert Consensus on Risk Assessment in Cardiac Arrhythmias: Use the Right Tool for the Right Outcome [1-3], to create tools for clinicians to perform rational and evidence-based risk stratification in cardiac arrhythmias. It is known that patients with cardiac diseases, or at high risk of developing a heart condition, undergo risk assessment by cardiologists and primary care physicians. There are several methods used for this risk assessment, and they differ with respect to availability, complexity, and usefulness in different patient populations. This document focuses on some of the many relevant clinical topics presented in the Consensus, whose statements are based on the best available evidence to date. In this review, 
we want to highlight some of the most relevant points of the Consensus and provide some thoughts on their importance.

\section{Comments on "General tools for risk assessment, strengths, limitations, and pretest probability"}

Proper evaluation of any patient includes as major and first step, a detailed medical history. This is really important to determine the arrhythmia patterns, its duration, triggers, and, very relevant, the mode of onset (beginning) and termination (end) of tachycardias. Also relevant are the accompanying symptoms when the event occurs, and, in cases with heart failure, the functional class (still mostly evaluated by the New York Heart Association (NYHA) classification) and left ventricular ejection fraction (LVEF) to guide diagnosis and to perform the best treatment for each patient [1-4].

After clinical history, the most straightforward and essential tool in arrhythmia evaluation is still the 12-lead electrocardiogram (ECG). With this tool, we can identify ventricular preexcitation, tachyarrhythmias, and conduction disturbances, but also the presence of structural heart disease, and many cardiac ion channel diseases ("channelopathies"). But the ECG is not only useful for diagnosis; there is growing data that confirms its utility for prognosis. For example, some $\mathrm{P}$ wave characteristics had been shown to be predictive of atrial fibrillation (AF) [5, 6]. $\mathrm{P}$ wave duration (atrial depolarization) is an independent risk factor for $\mathrm{AF}$ occurrence in 10 years [7]. QRS duration (depolarization component) has been associated with all-cause mortality among patients with heart failure [8]. QT interval measurement (as a surrogated of repolarization) is key for the diagnosis of both congenital and "acquired" long QT syndrome, but also for monitoring the effects of several drugs that prolongs the QT interval as has been clearly demonstrated during this coronavirus pandemic. Different ST segment and T wave (ST-T or repolarization components) characteristics could be predictors of malignant arrhythmias, as when macroscopic T-wave alternans appeared on any 12-lead ECG, Holter monitoring, or treadmill-stress test. A very specific ECG pattern called "Early repolarization syndrome" (not the traditional early repolarization pattern) has been established as a new entity with a high possibility of sudden cardiac death (SCD) and is easily observed in the 12-lead ECG [9]. Finally, ambulatory ECG monitoring (Holter monitoring) can register continuous heart rhythm and allow us to detect and quantify arrhythmias. To establish the burden of atrial and ventricular arrhythmias is relevant for treatment decisions, including drug treatment and catheter ablation. Advances on ambulatory monitoring include new personal portable devices, long-term monitoring through patch monitors, and implantable subcutaneous loop recorders (ILR).
New portable device (wearable/direct to consumer products) technology refers to several equipment that monitor physiological parameters (i.e., ECG) and can be used to facilitate arrhythmia detection, but it is imperative to integrate them into clinical context and physician judgment. The ILR provides long-term continuous monitoring up to 3 years, improving the diagnosis of unexplained syncope, allowing to provide specific treatment of tachyarrhythmias, and even to detect AF as a cause of "cryptogenic" stroke or ESUS, embolic stroke of undetermined source [1-3].

Many other data may also be acquired with new Holter monitoring systems. In this sense, 24-h heart rate variability can help to predict adverse outcomes in the subset of patients with ischemic cardiomyopathy [10].

\section{Comments on "Risk assessment of ventricular arrhythmias using imaging modalities"}

LVEF remains the most crucial parameter for SCD prediction, especially in subjects with structural heart disease in which it guides implantable cardioverter-defibrillator (ICD) implantation. Therefore, echocardiography, due to its large availability, is still the main tool for risk stratification of SCD. But primary prevention rate all over the world is still low, with only 1 to $5 \%$ of patients with an ICD implanted based upon low LVEF (LVEF > 35\%) [6, 11]. On the other hand, up to $70 \%$ of all SCD occur in individuals with a LVEF greater than $35 \%$ [11, 12]. These data implies that many patients that could be prevented from SCD are either not implanted with an ICD (when they should) or do not receive an ICD because an incomplete risk stratification. Using other imaging techniques, like cardiac magnetic resonance imaging (MRI) with late gadolinium enhancement, it is possible to broaden the spectrum of patients who can benefit from an ICD or other interventional therapies. For example, information about fibrosis or scar tissue could guide ventricular tachycardia (VT) ablation around scar reentry circuits [13, 14]. Quantification of myocardial fibrosis could guide ICD implantation in some diseases like hypertrophic cardiomyopathy. Unfortunately, this technology is not widely available in Latin American countries. Therefore, echocardiography is still the most frequently used imaging tool in Latin America, due to lower cost and availability.

\section{Comments on "Invasive electrophysiological study"}

Invasive electrophysiology (EP) studies are still a useful tool to identify the cause of unexplained syncope, mainly in subjects with previous myocardial infarction or other 
scar-related conditions (i.e., congenital heart disease) [15]. It can identify conduction disturbances in which a pacemaker is mandatory, VT in patients with an unclear indication for ablation or slight decrease of LVEF, and may have prognostic value for SCD in specific subgroups, like in asymptomatic patients with Brugada syndrome. It is also essential to know when we should not perform an EP study: (a) in patients with a LVEF $<35 \%$ (with or without ischemic heart disease) or other scenarios distinct than asymptomatic Brugada syndrome [1-3].

\section{Comments on "Biomarkers, tissue, and genetics"}

Biomarkers are useful to stratify many illnesses and are used with increasing frequency all over the world [1-3]. Nowadays, the value of molecular genetic studies is clear, for diagnosis and for risk stratification in channelopathies and many myocardial diseases. Unfortunately, both tools, biomarkers and molecular genetic studies, are difficult to be applied in most developing countries. Therefore, for molecular genetic diagnosis, collaborations with laboratories from Europe or the USA are crucial for Latin American patients [1-3].

\section{Comments on "How to assess risk for AF in people at higher risk for AF"}

AF has a prevalence in the Western world of $1-2 \%$, and it will increase as our population tends to be older $[16,17]$. Risk assessment for AF is crucial since this arrhythmia is associated with the risk of stroke, cognitive impairment, heart failure, and even death $[18,19]$. Risk assessment should focus on two main areas: risk of developing AF and risk of developing AF-related complications. The following must be considered for the former [1-3]. Age continues to be one of the most important risk factors for developing AF. Gender has a special interest since women have higher incidence of AF, usually have more comorbidities, are less symptomatic, and are at higher risk of complications [20]. Heart failure has a bidirectional relationship with $\mathrm{AF}$ as subjects with heart failure are at increasing risk of developing AF but also AF could precipitate heart failure in specific subsets of patients. In both situations, the combination of heart failure and AF increases the risk of suffering AF-related complications [21-23]. Frequent interrogation of implantable devices (ICD or CRT-D devices) commonly used in heart failure patients, alongside with an increased use of "home monitoring" platforms, is crucial for an early diagnosis and management of AF. Careful consideration of individual risk factors like obesity, diabetes, sleep apnea, and structural heart disease is emphasized, as well as the use of clinical risk scores [1-3]. Clinical tools go from amazingly simple strategies, as to train patients on pulse palpation, to more complex analysis of risk factors with the use of $\mathrm{CHA}_{2} \mathrm{DS}_{2}$-VASc score to stratify patients to oral anticoagulation therapy. Nowadays, it is possible to download many applications that include calculators for $\mathrm{CHA}_{2} \mathrm{DS}_{2}$-VASc and HAS-BLED scores.

\section{Comments on "Risk of developing complications because of AF"}

In the Consensus, cognitive assessment is highly recommended in AF patients since it has been clearly shown that $\mathrm{AF}$ is a risk factor for cognitive decline or impairment of cognitive function [24]. This may be related to directly to manifest or silent stroke but also to other mechanisms that are independent from thromboembolism. There is evidence that early anticoagulation therapy using risk factor stratification may reduce the rate of this cognitive decline [24]. Therefore, cardiologists should interact with their counterparts, neurologists, in order to prevent this deficit.

\section{Comments on "How to assess risk for adverse outcome (disease progression or death) in patients with AF"}

Stroke is the most known adverse outcome in AF [23-25] and anticoagulation therapy is the cornerstone therapy for stroke prevention in AF. Stroke risk scores must be used to guide therapy and the most widely used is the $\mathrm{CHA}_{2} \mathrm{DS}_{2}$-VASc [26]. Male patients with a score $>1$ or woman with $>2$ points should be considered for long-term oral anticoagulation. For high-risk patients in which longterm anticoagulation is contraindicated, left atrial appendage occlusion (LAAO) has emerged as an alternative therapy. Although there is no definitive evidence on its use, randomized trials found a non-inferior strategy in LAAO when compared to warfarin [27]. More solid evidence is needed on this topic before its widespread use.

Catheter ablation is an acceptable therapy in symptomatic patients with AF and may have benefits in hard clinical endpoints (death and hospitalization for worsening heart failure) in selected populations, like patients with impaired LVEF as shown in the CASTLE-AF trial [28-30]. In the CABANA trial, where not only patients with impaired LVEF were included but hard clinical endpoints did also not differ between drug and ablation therapy [31].

Discrepancy regarding a rhythm or rate control strategy has been a discussion since the publication of the AFFIRM trial in the early 2000 [32] that did not show any difference in outcomes. However, the recently published EAST-AFNET 4 
Trial showed that the ablation strategy has a statistically significant difference in the composite primary endpoint (death and stroke) that favored a rhythm-control strategy $(3.9 \%$ vs $5.0 \% P=0.005$ ) [33]. It is important to address that EAST/ AFNET 4 trial could not be included in this Consensus, as it was recently released (August 2020). Another recent trial on cryoballoon ablation versus drugs also confirms the EASTAFNET 4 results [34].

\section{Comments on "How to assess risk for VT in specific populations"}

Coronary heart disease is the most frequent etiology of SCD, with approximately $70 \%$ of cases [35]. For primary prevention of SCD, current approach to risk stratification relies mainly on the evaluation of LVEF: values below 30-35\% allow the identification of ICD candidates, who are at the highest relative risk of SCD. In other words, many patients with EF $35 \%$ and a high risk of VT/VF are not protected, and patients with a LVEF > 35\% account for the highest absolute number of SCDs [36]. For this reason, many researchers emphasize that EF is an inadequate marker for detecting patients who are at high risk for SCD despite having a normal or subnormal EF.

In secondary prevention, SCD risk is significantly higher, and thus risk stratification is certainly more standardized. Both the ischemic substrate and the ischemic triggers for malignant ventricular arrhythmias must be evaluated whenever considered appropriate with coronary angiogram, functional ischemic evaluation by nuclear scan, stress-echocardiography, or MRI [15, 36, 37].

Non-ischemic HF includes a heterogeneous group of patients with reduced ventricular function due to cardiomyopathies from different etiologies, and at high risk for VT. Reduced cardiac function remains a powerful predictor of VT and appropriate ICD therapy in these patients as a primary prevention. Cardiac MRI shows promising results in some subsets [38, 39].

Inflammatory cardiomyopathies encompass a broad spectrum of disorders characterized by myocardial inflammation as the primary cause of cardiac dysfunction. In patients who present with ventricular arrhythmias and diagnosed with non-ICM, the incidence of inflammatory cardiomyopathy may be as high as $50 \%$ [40].

Cardiac MRI scan is the gold standard for diagnosing myocarditis and inflammatory cardiomyopathies [41]. The presence of late gadolinium enhancement is significantly associated with increased risk of adverse cardiac events. Although randomized data on the possible use of a higher EF for risk stratification in these patient populations is lacking, given the risk of VT noted in retrospective studies, the use of MRI and cardiac positron emission tomography to evaluate the etiology of non-ischemic heart disease is warranted.

Ventricular arrhythmias in patients with congenital heart disease may be observed the pediatric age group but also in adults with repaired congenital defects group [42]. In the pediatric patient with congenital heart disease, ventricular overload, surgical scars and patches or baffles, ventricular dysfunction, and previous conduction defects are recognized risk factors for VT $[43,44]$. In adult patients with congenital heart disease, an increasing group in Latin American countries, VTs are mainly observed after correction of tetralogy of Fallot and left ventricular outflow tract defects [45]. Older age at surgery, poor hemodynamic status, and prolonged QRS represent the most common risk factors for ventricular arrhythmias. In adult patients with congenital heart disease,

In Arrhythmogenic Right Ventricular Cardiomyopathy, the most important features of a high arrhythmic risk include sustained ventricular arrhythmias, non-fatal cardiac arrest, severe right and/or left ventricular dysfunction, and the presence of a positive genotype [46]. Ambulatory ECG monitoring is crucial to detect premature ventricular complex burden or the presence of non-sustained VT. Inducibility of VT/ VF on EPS can prompt an ICD therapy in these patients [46]. Abnormal cardiac MRI is an independent predictor of clinical events with a cumulative effect of the abnormalities including morphology, wall motion, and fat/fibrosis [47].

In patients with Chagas' disease, a disease with a high prevalence in Central and South American countries, the highest risk of death is observed associated with the presence of HF with a NYHA class III/IV and non-sustained VT on Holter or patients in NYHA class I/II with left ventricular dysfunction and NSVT on Holter. All those patients should be considered candidates for invasive therapeutic management [48]. In patients with syncope and a bundle branch block, an invasive EPS is useful in assessing risk of sustained ventricular arrhythmias [49]. When available, cardiac MRI should be considered to evaluate for arrhythmogenic substrate as part of a risk stratification strategy in those patients with cardiomyopathy.

\section{Conclusions}

The Expert Consensus developed by the four major EP international societies have an important role for helping guide clinicians in conditions associated with arrhythmias. Although a wide range of tools is available for risk assessment, choosing the best method and tool, considering the individual patients' characteristics and the suspected arrhythmia, is not always an easy decision. Even though many of the content of this document is not easily available in our region, there are clearly many tools that are relevant to clinical cardiologists and arrhythmia specialists working 
on the field in Latin America and that can lead to better care for our patients.

\section{References}

1. Nielsen JC, Lin Y-J, de Oliveira Figueiredo MJ, Sepehri Shamloo A, Alfie A, Boveda S, et al. European Heart Rhythm Association (EHRA)/Heart Rhythm Society (HRS)/Asia Pacific Heart Rhythm Society (APHRS)/Latin American Heart Rhythm Society (LAHRS) expert consensus on risk assessment in cardiac arrhythmias: use the right tool for the right outcome. Heart Rhythm. 2020;17(9):e269-316. Available from: http://www.ncbi.nlm.nih. gov/pubmed/32553607.

2. Nielsen JC, Lin Y-J, de Oliveira Figueiredo MJ, Sepehri Shamloo A, Alfie A, Boveda S, et al. European Heart Rhythm Association (EHRA)/Heart Rhythm Society (HRS)/Asia Pacific Heart Rhythm Society (APHRS)/Latin American Heart Rhythm Society (LAHRS) expert consensus on risk assessment in cardiac arrhythmias: use the right tool for the right outcome, in the rigth population. Europace. 2020; Available from: http://www.ncbi.nlm.nih. gov/pubmed/32538434.

3. Nielsen JC, Lin Y-J, de Oliveira Figueiredo MJ, Sepehri Shamloo A, Alfie A, Boveda S, et al. European Heart Rhythm Association (EHRA)/Heart Rhythm Society (HRS)/Asia Pacific Heart Rhythm Society (APHRS)/Latin American Heart Rhythm Society (LAHRS) expert consensus on risk assessment in cardiac arrhythmias: use the right tool for the right outcome. J Arrhythmia. 2020;36(4):553-607. Available from: http://www.ncbi.nlm.nih. gov/pubmed/32782627.

4. Apostolakis S, Lane DA, Buller H, Lip GYH. Comparison of the CHADS2, CHA2DS2-VASc and HAS-BLED scores for the prediction of clinically relevant bleeding in anticoagulated patients with atrial fibrillation: the AMADEUS trial. Thromb haemost. 2013;110(5):1074-9. Available from: http://www.ncbi.nlm.nih. gov/pubmed/24048467.

5. Rubio Campal JM, Benezet-Mazuecos J, Iglesias Bravo JA, Sánchez Borque P, Miracle Blanco Á, de la Vieja Alarcón JJ, et al. P-wave and interatrial block: new predictor for atrial high rate episodes in patients with cardiac implantable electronic devices. Pacing Clin Electrophysiol. 2018;41(3):223-8. Available from: http://www.ncbi.nlm.nih.gov/pubmed/29327362.

6. Nielsen JB, Kühl JT, Pietersen A, Graff C, Lind B, Struijk JJ, et al. $\mathrm{P}$-wave duration and the risk of atrial fibrillation: results from the Copenhagen ECG Study. Heart Rhythm. 2015;12(9):1887-95. Available from: http://www.ncbi.nlm.nih.gov/pubmed/25916567.

7. de Bacquer D, Willekens J, de Backer G. Long-term prognostic value of p-wave characteristics for the development of atrial fibrillation in subjects aged 55 to 74 years at baseline. Am J Cardiol. 2007;100(5):850-4. Available from: http://www.ncbi.nlm.nih.gov/ pubmed/17719332.

8. Alfraidi H, Seifer CM, Hiebert BM, Torbiak L, Zieroth S, McIntyre WF. Relation of increasing QRS duration over time and cardiovascular events in outpatients with heart failure. Am J Cardiol. 2019;124(12):1907-11. Available from: http://www.ncbi.nlm.nih. gov/pubmed/31668343.

9. Márquez MF. New observations on the "early repolarization syndrome." Heart Rhythm. 2012;9(1):84-5. https://doi.org/10.1016/j. hrthm.2011.08.028.

10. Sessa F, Anna V, Messina G, Cibelli G, Monda V, Marsala G, et al. Heart rate variability as predictive factor for sudden cardiac death. Aging. 2018;10(2):166-77. Available from: http://www.ncbi.nlm. nih.gov/pubmed/29476045.
11. Stecker EC, Vickers C, Waltz J, Socoteanu C, John BT, Mariani $\mathrm{R}$, et al. Population-based analysis of sudden cardiac death with and without left ventricular systolic dysfunction: two-year findings from the Oregon Sudden Unexpected Death Study. J Am Coll Cardiol. 2006;47(6):1161-6. Available from: http://www. ncbi.nlm.nih.gov/pubmed/16545646.

12. Gorgels APM, Gijsbers C, de Vreede-Swagemakers J, Lousberg A, Wellens HJJ. Out-of-hospital cardiac arrest--the relevance of heart failure. The Maastricht Circulatory Arrest Registry. Eur Heart J. 2003;24(13):1204-9. Available from: http://www.ncbi.nlm.nih. gov/pubmed/12831814.

13. Piers SRD, Tao Q, van Huls van Taxis CFB, Schalij MJ, van der Geest RJ, Zeppenfeld K. Contrast-enhanced MRI-derived scar patterns and associated ventricular tachycardias in nonischemic cardiomyopathy: implications for the ablation strategy. Circ Arrhythm Electrophysiol. 2013;6(5):875-83. Available from: http://www.ncbi.nlm.nih.gov/pubmed/24036134.

14. White JA, Fine NM, Gula L, Yee R, Skanes A, Klein G, et al. Utility of cardiovascular magnetic resonance in identifying substrate for malignant ventricular arrhythmias. Circ Cardiovasc Imaging. 2012;5(1):12-20. Available from: http://www.ncbi.nlm.nih.gov/ pubmed/22038987.

15. Al-Khatib SM, Stevenson WG, Ackerman MJ, Bryant WJ, Callans DJ, Curtis AB, et al. 2017 AHA/ACC/HRS guideline for management of patients with ventricular arrhythmias and the prevention of sudden cardiac death. J Am Coll Cardiol. 2018;72(14):e91220. Available from: http://www.ncbi.nlm.nih.gov/pubmed/29097 296.

16. Staerk L, Sherer JA, Ko D, Benjamin EJ, Helm RH. atrial fibrillation: epidemiology, pathophysiology, and clinical outcomes. Circ Res. 2017;120(9):1501-17.

17. Márquez MF, Baños-González MA, Guevara-Valdivia ME, Vázquez-Acosta J, de Los Ríos Ibarra MO, Aguilar-Linares JA, Jiménez-Cruz M, Matadamas-Hernández N, Camacho-Casillas R, Magaña-Magaña R, Rojel-Martínez U, Alcocer-Gamba MA, Lara-Vaca S, Rodríguez-Reyes H, Islava-Gálvez MA, BetancourtHernández LE, Reyes-Reyes N, Beltrán-Gámez ME, Cantú-Brito C, Baños-Velasco AZ, Del Rivero Morfin PJ, González-Hermosillo JA. Anticoagulation therapy by age and embolic risk for nonvalvular atrial fibrillation in Mexico, an upper-middle-income country: the CARMEN-AF registry. Glob Heart. 2020;15(1):32. https://doi.org/10.5334/gh.767.

18. Dagres N, Chao T-F, Fenelon G, Aguinaga L, Benhayon D, Benjamin EJ, et al. European Heart Rhythm Association (EHRA)/ Heart Rhythm Society (HRS)/Asia Pacific Heart Rhythm Society (APHRS)/Latin American Heart Rhythm Society (LAHRS) expert consensus on arrhythmias and cognitive function: what is the best practice? Europace. 2018;20(9):1399-421. Available from: http:// www.ncbi.nlm.nih.gov/pubmed/29562326.

19. Hindricks G, Potpara T, Dagres N, Arbelo E, Bax JJ, BlomströmLundqvist C, et al. 2020 ESC Guidelines for the diagnosis and management of atrial fibrillation developed in collaboration with the European Association of Cardio-Thoracic Surgery (EACTS). Eur Heart J. 2020; Available from: https://academic.oup.com/eurheartj/advance-article/doi/https://doi.org/10.1093/eurheartj/ehaa6 $12 / 5899003$

20. González-Hermosillo J, Baños-González MA, Guevara-Valdivia ME, Vázquez-Acosta JA, de Los Ríos Ibarra MO, Aguilar-Linares KA, Cantú-Brito C, Leiva-Pons JL, Pozas-Garza G, Favela-Pérez EA, Márquez MF; CARMEN-AF Committees and Investigators. Gender differences and management of stroke risk of nonvalvular atrial fibrillation in an upper middle-income country: insights from the CARMEN-AF registry. Int J Cardiol Heart Vasc. 2019;22:117-122. https://doi.org/10.1016/j.ijcha.2018.12.017.

21. Allan V, Honarbakhsh S, Casas J-P, Wallace J, Hunter R, Schilling $\mathrm{R}$, et al. Are cardiovascular risk factors also associated with the 
incidence of atrial fibrillation? A systematic review and field synopsis of 23 factors in 32 population-based cohorts of 20 million participants. Thromb Haemost. 2017;117(5):837-50. Available from: http://www.ncbi.nlm.nih.gov/pubmed/28229164.

22. Wang TJ, Massaro JM, Levy D, Vasan RS, Wolf PA, D'Agostino $\mathrm{RB}$, et al. A risk score for predicting stroke or death in individuals with new-onset atrial fibrillation in the community: the Framingham Heart Study. JAMA. 2003;290(8):1049-56. Available from: http://www.ncbi.nlm.nih.gov/pubmed/12941677.

23. Healey JS, Oldgren J, Ezekowitz M, Zhu J, Pais P, Wang J, et al. Occurrence of death and stroke in patients in 47 countries 1 year after presenting with atrial fibrillation: a cohort study. Lancet (London, England). 2016;388(10050):1161-9. Available from: http://www.ncbi.nlm.nih.gov/pubmed/27515684.

24. Dagres N, Chao TF, Fenelon G, Aguinaga L, Benhayon D, Benjamin EJ, Bunch TJ, Chen LY, Chen SA, Darrieux F, de Paola A, Fauchier L, Goette A, Kalman J, Kalra L, Kim YH, Lane DA, Lip GYH, Lubitz SA, Márquez MF, Potpara T, Pozzer DL, Ruskin JN, Savelieva I, Teo WS, Tse HF, Verma A, Zhang S, Chung MK; ESC Scientific Document Group. European Heart Rhythm Association (EHRA)/Heart Rhythm Society (HRS)/Asia Pacific Heart Rhythm Society (APHRS)/Latin American Heart Rhythm Society (LAHRS) expert consensus on arrhythmias and cognitive function: what is the best practice? Europace. 2018;20(9):1399-1421. https://doi.org/10.1093/europace/euy046.

25. Fauchier L, Samson A, Chaize G, Gaudin A-F, Vainchtock A, Bailly $\mathrm{C}$, et al. Cause of death in patients with atrial fibrillation admitted to French hospitals in 2012: a nationwide database study. Open Heart. 2015;2(1):e000290. Available from: http://www.ncbi. nlm.nih.gov/pubmed/26688739.

26. Fauchier L, Clementy N, Bisson A, Ivanes F, Angoulvant D, Babuty D, et al. Should atrial fibrillation patients with only 1 nongender-related CHA2DS2-VASc risk factor be anticoagulated? Stroke. 2016;47(7):1831-6. Available from: http://www.ncbi.nlm. nih.gov/pubmed/27231269.

27. Reddy VY, Doshi SK, Kar S, Gibson DN, Price MJ, Huber K, et al. 5-year outcomes after left atrial appendage closure: from the PREVAIL and PROTECT AF trials. J Am Coll Cardiol. 2017;70(24):2964-75. Available from: http://www.ncbi.nlm.nih. gov/pubmed/29103847.

28. Wang TJ, Larson MG, Levy D, Vasan RS, Leip EP, Wolf PA, et al. Temporal relations of atrial fibrillation and congestive heart failure and their joint influence on mortality: the Framingham Heart Study. Circulation. 2003;107(23):2920-5. Available from: http://www.ncbi.nlm.nih.gov/pubmed/12771006.

29. Deedwania PC, Lardizabal JA. Atrial fibrillation in heart failure: a comprehensive review. Am J Med. 2010;123(3):198-204. Available from: http://www.ncbi.nlm.nih.gov/pubmed/20193823.

30. Marrouche NF, Brachmann J, Andresen D, Siebels J, Boersma L, Jordaens L, et al. Catheter ablation for atrial fibrillation with heart failure. N Engl J Med. 2018;378(5):417-27. Available from: http://www.ncbi.nlm.nih.gov/pubmed/29385358.

31. Packer DL, Mark DB, Robb RA, Monahan KH, Bahnson TD, Poole JE, et al. Effect of catheter ablation vs antiarrhythmic drug therapy on mortality, stroke, bleeding, and cardiac arrest among patients with atrial fibrillation: the CABANA randomized clinical trial. JAMA. 2019;321(13):1261-74. Available from: http://www. ncbi.nlm.nih.gov/pubmed/30874766.

32. Wyse DG, Waldo AL, DiMarco JP, Domanski MJ, Rosenberg Y, Schron EB, et al. A comparison of rate control and rhythm control in patients with atrial fibrillation. N Engl J Med. 2002 Dec 5 [cited 2014 Jan 4];347(23):1825-33. Available from: http://ukpmc.ac. uk/abstract/MED/12466506.

33. Kirchhof P, Camm AJ, Goette A, Brandes A, Eckardt L, Elvan A, et al. Early rhythm-control therapy in patients with atrial fibrillation. N Engl J Med. 2020; Available from: http://www. ncbi.nlm.nih.gov/pubmed/32865375.

34. Andrade JG, Wells GA, Deyell MW, Bennett M, Essebag V, Champagne J, Roux JF, Yung D, Skanes A, Khaykin Y, Morillo C, Jolly U, Novak P, Lockwood E, Amit G, Angaran P, Sapp J, Wardell S, Lauck S, Macle L, Verma A; EARLY-AF Investigators. Cryoablation or drug therapy for initial treatment of atrial fibrillation. N Engl J Med. 2021;384(4):305-15. doi: https://doi. org/10.1056/NEJMoa2029980.

35. Rodríguez-Reyes $\mathrm{H}$, Muñoz Gutiérrez M, Márquez MF, Pozas Garza G, Asensio Lafuente E, Ortíz Galván F, Lara Vaca S, Mariona Montero VA. Muerte súbita cardiaca. Estratificación de riesgo, prevención y tratamiento [Sudden cardiac death. Risk stratification, prevention and treatment]. Arch Cardiol Mex. 2015;85(4):329-36. Spanish. https://doi.org/10.1016/j.acmx.2015. 06.002 .

36. Moss AJ, Hall WJ, Cannom DS, Daubert JP, Higgins SL, Klein H, et al. Improved survival with an implanted defibrillator in patients with coronary disease at high risk for ventricular arrhythmia. Multicenter Automatic Defibrillator Implantation Trial Investigators. N Engl J Med. 1996;335(26):1933-40. Available from: http:// www.ncbi.nlm.nih.gov/pubmed/8960472.

37. Priori SG, Blomström-Lundqvist C, Mazzanti A, Blom N, Borggrefe M, Camm J, et al. 2015 ESC Guidelines for the management of patients with ventricular arrhythmias and the prevention of sudden cardiac death: the task force for the management of patients with ventricular arrhythmias and the prevention of sudden cardiac death of the Europe. Eur Heart J. 2015;36(41):2793-867. Available from: http://www.ncbi.nlm.nih.gov/pubmed/26320108.

38. Kuruvilla S, Adenaw N, Katwal AB, Lipinski MJ, Kramer CM, Salerno M. Late gadolinium enhancement on cardiac magnetic resonance predicts adverse cardiovascular outcomes in nonischemic cardiomyopathy: a systematic review and meta-analysis. Circ Cardiovasc Imaging. 2014;7(2):250-8. Available from: http://www.ncbi.nlm.nih.gov/pubmed/24363358.

39. di Marco A, Anguera I, Schmitt M, Klem I, Neilan TG, White JA, et al. Late gadolinium enhancement and the risk for ventricular arrhythmias or sudden death in dilated cardiomyopathy: systematic review and meta-analysis. JACC Heart failure. 2017;5(1):2838. Available from: http://www.ncbi.nlm.nih.gov/pubmed/28017 348.

40. Tung R, Bauer B, Schelbert H, Lynch JP, Auerbach M, Gupta $\mathrm{P}$, et al. Incidence of abnormal positron emission tomography in patients with unexplained cardiomyopathy and ventricular arrhythmias: The potential role of occult inflammation in arrhythmogenesis. Heart Rhythm. 2015;12(12):2488-98. Available from: http://www.ncbi.nlm.nih.gov/pubmed/26272522.

41. Smedema J-P, Snoep G, van Kroonenburgh MPG, van Geuns R-J, Dassen WRM, Gorgels APM, et al. Evaluation of the accuracy of gadolinium-enhanced cardiovascular magnetic resonance in the diagnosis of cardiac sarcoidosis. J Am Coll Cardiol. 2005;45(10):1683-90. Available from: http://www.ncbi.nlm.nih. gov/pubmed/15893188.

42. Hernández-Madrid A, Paul T, Abrams D, Aziz PF, Blom NA, Chen J, et al. Arrhythmias in congenital heart disease: a position paper of the European Heart Rhythm Association (EHRA), Association for European Paediatric and Congenital Cardiology (AEPC), and the European Society of Cardiology (ESC) Working Group on Grown-up Congeni. Europace. 2018;20(11):1719-53. Available from: http://www.ncbi.nlm.nih.gov/pubmed/29579186.

43. van Hare GF, Javitz H, Carmelli D, Saul JP, Tanel RE, Fischbach PS, et al. Prospective assessment after pediatric cardiac ablation: demographics, medical profiles, and initial outcomes. J Cardiovasc Electrophysiol. 2004;15(7):759-70. Available from: http:// www.ncbi.nlm.nih.gov/pubmed/15250858. 
44. Brugada J, Blom N, Sarquella-Brugada G, Blomstrom-Lundqvist C, Deanfield J, Janousek J, et al. Pharmacological and non-pharmacological therapy for arrhythmias in the pediatric population: EHRA and AEPC-Arrhythmia Working Group joint consensus statement. Europace. 2013;15(9):1337-82. Available from: http:// www.ncbi.nlm.nih.gov/pubmed/23851511.

45. Harrison DA, Harris L, Siu SC, MacLoghlin CJ, Connelly MS, Webb GD, et al. Sustained ventricular tachycardia in adult patients late after repair of tetralogy of Fallot. J Am Coll Cardiol. 1997;30(5):1368-73. Available from: http://www.ncbi.nlm.nih. gov/pubmed/9350941.

46. Gandjbakhch E, Redheuil A, Pousset F, Charron P, Frank R. Clinical diagnosis, imaging, and genetics of arrhythmogenic right ventricular cardiomyopathy/dysplasia: JACC state-of-the-art review. J Am CollCardiol. 2018;72(7):784-804. https://doi.org/10.1016/j. jacc.2018.05.065.

47. Deac M, Alpendurada F, Fanaie F, Vimal R, Carpenter J-P, Dawson A, et al. Prognostic value of cardiovascular magnetic resonance in patients with suspected arrhythmogenic right ventricular cardiomyopathy. Int J Cardiol. 2013;168(4):3514-21. Available from: http://www.ncbi.nlm.nih.gov/pubmed/23701935.

48. Rassi A, Rassi A. Rassi score: another external validation with high performance in patients with chagas cardiomyopathy. J Am Coll Cardiol. 2019;73(13):1734-5. Available from: http://www. ncbi.nlm.nih.gov/pubmed/30947930.

49. Martinelli Filho M, Sosa E, Nishioka S, Scanavacca M, Bellotti G, Pileggi F. Clinical and electrophysiologic features of syncope in chronic chagasic heart disease. J Cardiovasc Electrophysiol. 1994;5(7):563-70. Available from: http://www.ncbi.nlm.nih.gov/ pubmed/7987526.

Publisher's note Springer Nature remains neutral with regard to jurisdictional claims in published maps and institutional affiliations. 